\title{
EINFACH ODER ANSPRUCHSLOS? \\ ÜBER DAS PUNKTKREISORNAMENT IM 6. JAHRHUNDERT ANHAND DREIER FIBELN AUS KOMITAT TOLNA
}

\author{
ISTVÁN KONCZ - JÁNOS GÁBOR ÓDOR*
}

\begin{abstract}
The study addresses the find types decorated with ring-and-dot motifs and the interpretation of this motif in relation to three brooches from Tolna County. Although the three brooches are decorated in a similar manner, their forms differ, reflecting cultural contacts with entirely different regions.
\end{abstract}

Keywords: 6th century, brooch, ring-and-dot motif, Transdanubia

A tanulmány a 6. századi, pontkörrel diszített tárgyak körét és általában a díszitésmód értelmezését vizsgálja a Tolna megyéből származó három fibula kapcsán. A fibulák díszitése ugyan egyezik, de formájuk különböző irányokba mutató kulturális kapcsolatokra utal.

Kulcsszavak: 6. század, fibula, pontkördiszités, Dunántúl

\section{Der Fundort und seine Umstände}

In jüngerer Vergangenheit sind uns drei aufgrund ihrer Verzierung und Zeitstellung miteinander $\mathrm{zu}$ verbindende Fibeln ins Blickfeld gekommen, die in einem engeren Gebiet, im Komitat Tolna, als Streufunde entdeckt wurden. Sie gelangten zum Sammler Zsolt Zsiga in Pincehely, der uns die Funde zur Aufarbeitung zur Verfügung stellte. Der genaue Fundort der Scheibenfibel ist nicht bekannt; die Finder konnten nur sagen, dass sie aus dem Kom. Tolna stammt. Die Vogelfibel kam am Fundort Pincehely-Papsziget zum Vorschein. Das Gebiet ist eine sich am linken Kaposufer, nördlich vom Zufluss der Fürgedi-víz erhebende, einst völlig vom Wasser eingeschlossene, wirkliche Insel. Auf dem derzeit umgepflügten Hügel sind reiche urzeitliche und sich bis auf den südlichen Teil erstreckende römerzeitliche Siedlungsreste bekannt. Die Fibel stammt aus letzterem Teil. Die Pferdefibel wurde bei Sárszentlőrinc-Siópart gefunden. Der Fundort liegt von den Häusern an der Peripherie der Gemeinde am rechten Sioufer ca. $800 \mathrm{~m}$ nach Norden, $600 \mathrm{~m}$ südlich des Hügels vom im Mittelalter zerstörten Dorf Csetény. Westlich vom Überschwemmungsgebiet des Sió, auf dem Plateau des steil aufragenden Hügelzugs fanden Metalldetektorsucher vor einigen Jahren auf einem $60 \times 80 \mathrm{~m}$ großen Gelände die Pferdefibel zusammen mit sonstigen Funden (Silberarmringfragmente, Stücke einer zerbrochenen großen Silberfibel), die leider verschollen sind, anderswohin kamen. Südlich vom Fundort ziehen sich früh- und spätrömerzeitliche Siedlungsreste hin (Abb. 1).

\footnotetext{
A kézirat érkezett: 2016. március 1.

* István Koncz. Eötvös Loránd Tudományegyetem Régészettudományi Intézete, 1088 Budapest, Múzeum krt. 4/B; fredgar22@gmail.com

János Gábor Ódor. Wosinsky Mór Múzeum, 7100 Szekszárd, Szent István tér 26.; odorjanos@gmail.com
} 


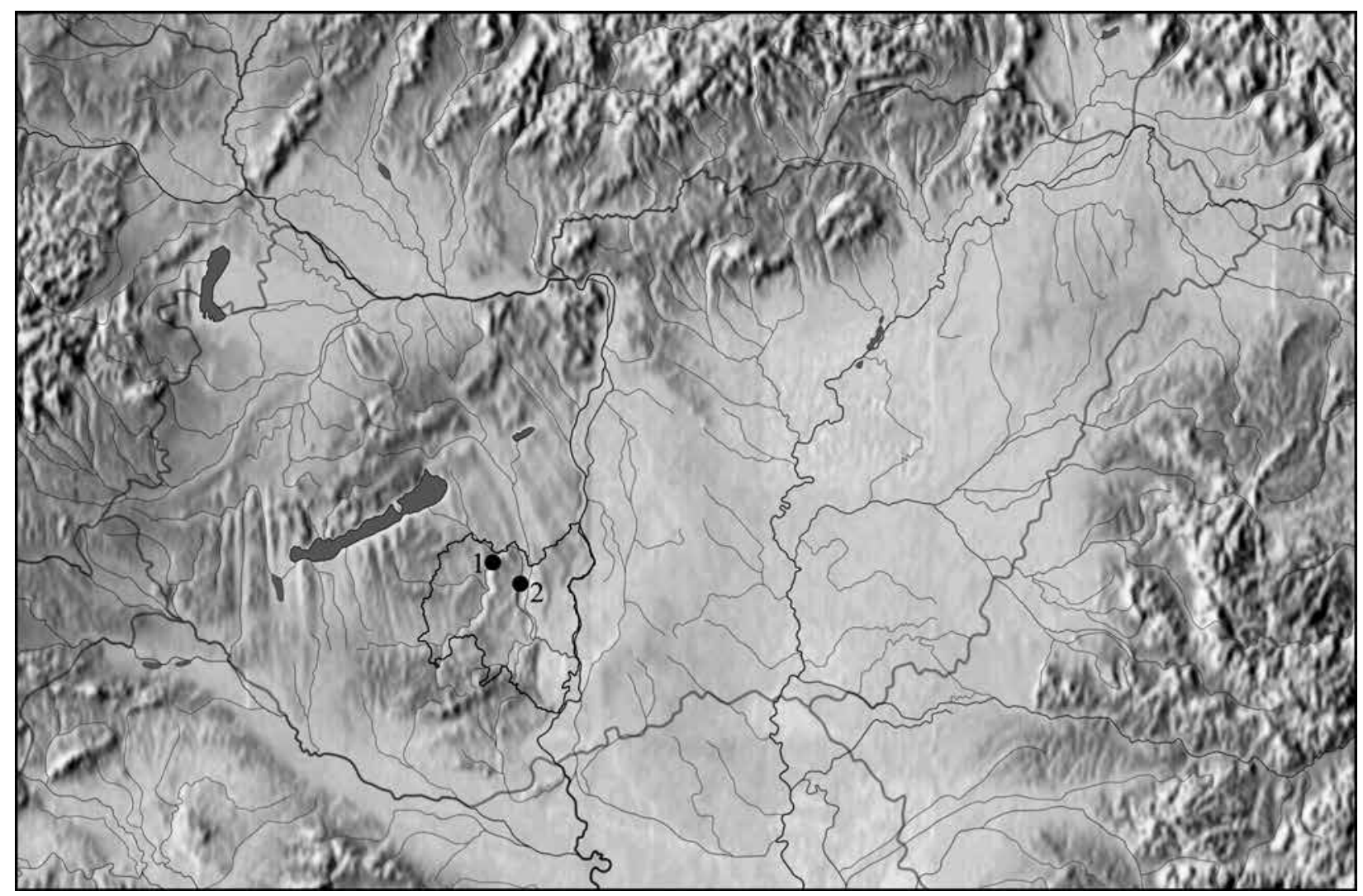

Abb. 1. Die Fundorte. 1: Sárszentlőrinc; 2: Pincehely

1. kép. A lelőhelyek. 1: Sárszentlőrinc; 2: Pincehely

\section{Die Vogelfibel}

Nach links blickende, stilisierte, bronzene Vogelfibel, Länge $4,3 \mathrm{~cm}$, größte Breite $1,2 \mathrm{~cm}$. Betont sind nur der krumme - raubvogelähnliche - Schnabel und die Schwanzfedern gekennzeichnet. Die ganze Oberfläche ist mit einer Art von Punktkreisen verziert, die unregelmäßig, in unterschiedlicher Entfernung voneinander verteilt sind. Auf der Rückseite verläuft ein schwach herausragender Längsrücken, aus dem sich die mitgegossene Federhalterung und der Nadelhalter mit umgebogenem Ende hervorheben. Die Nadel fehlt (Abb. 2).

Eine ganz genaue Formparallele der Vogelfibel von Pincehely ist derzeit nicht bekannt. Ähnlich geformte stilisierte Vogelfibeln, an denen nur Schnabel und Schwanzfedern zu erkennen sind, gibt es unter anderem in der Sammlung von Gertrud Thiry, aus der Welt der westlichen Merowinger. ${ }^{1}$ Zwei Vogelfibeln in Thirys Arbeit

1 Gertrud Thiry hat die Vogelfibeln nicht aufgrund der Form, sondern der Verzierung gruppiert. Die stilisierte Form von Sárszentlőrinc ist vor allem für den Typ der graviertverzierten Vogelfibeln bezeichnend. THIRY 1939, Taf. 15.333-335 und Taf. 18.411. waren mit ähnlichen Punktkreisen verziert wie die von Sárszentlőrinc. Die Verzierung des Exemplars vom Fundort Montigny en Arrouaise

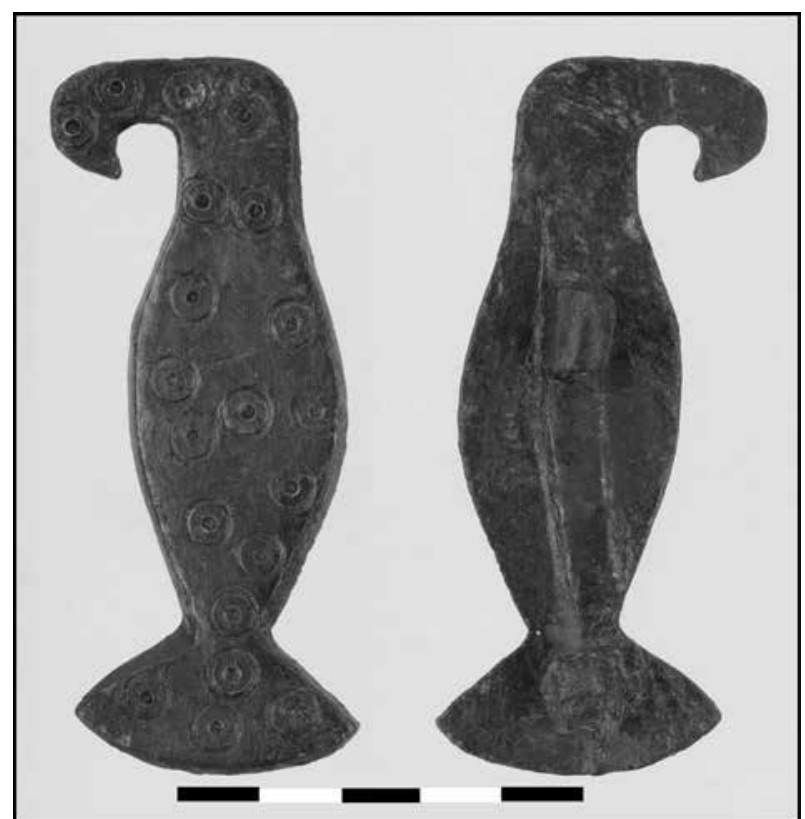

Abb. 2. Vogelfibel. Pincehely (Foto: Wosinsky Mór Megyei Múzeum) - 2. kép. Madárfibula. Pincehely (fotó: Wosinsky Mór Megyei Múzeum) 


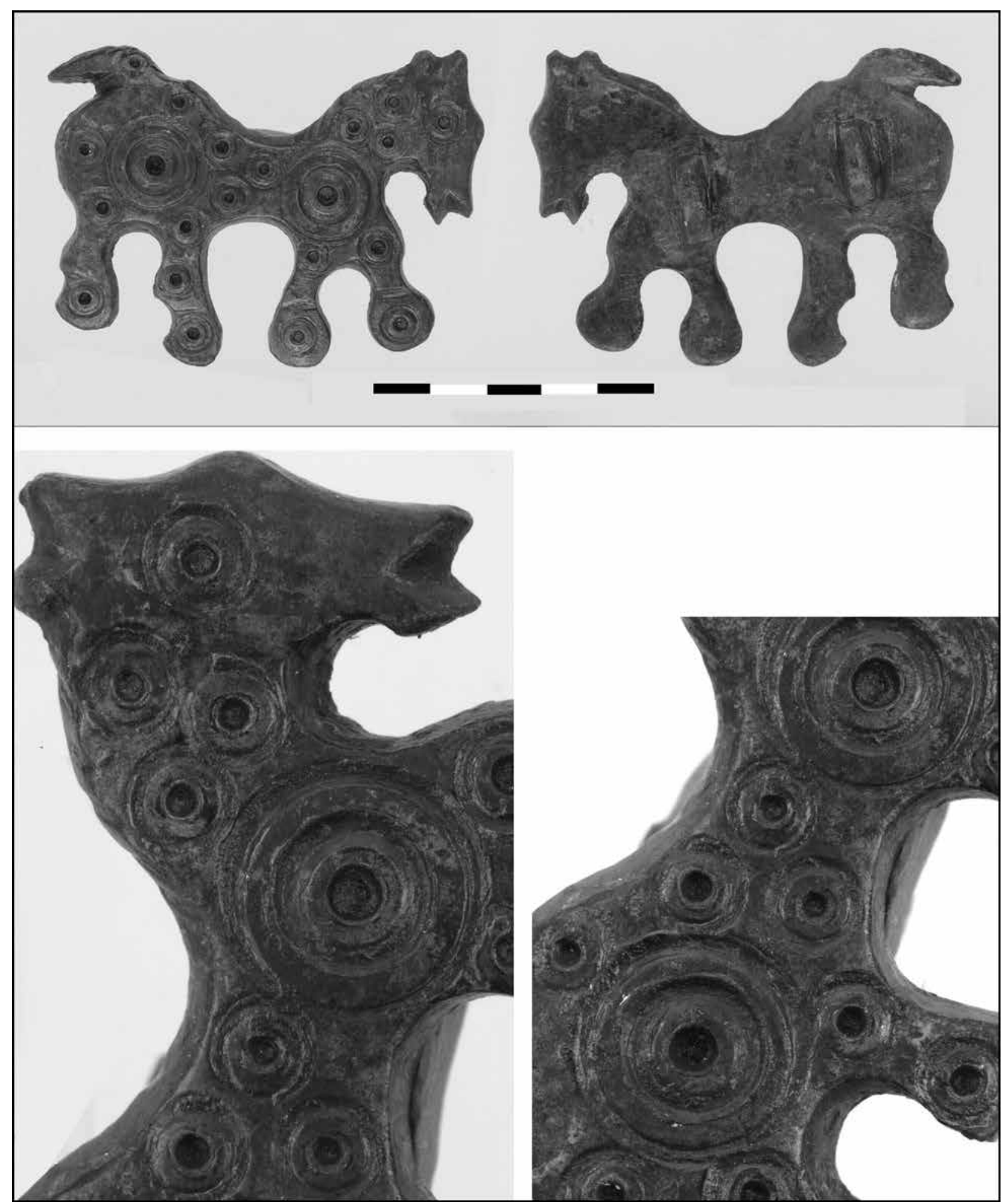

Abb. 3. Pferdefibel. Sárszentlórinc (Foto: Wosinsky Mór Megyei Múzeum)

3. kép. Lófibula. Sárszentloorinc (fotó: Wosinsky Mór Megyei Múzeum) 


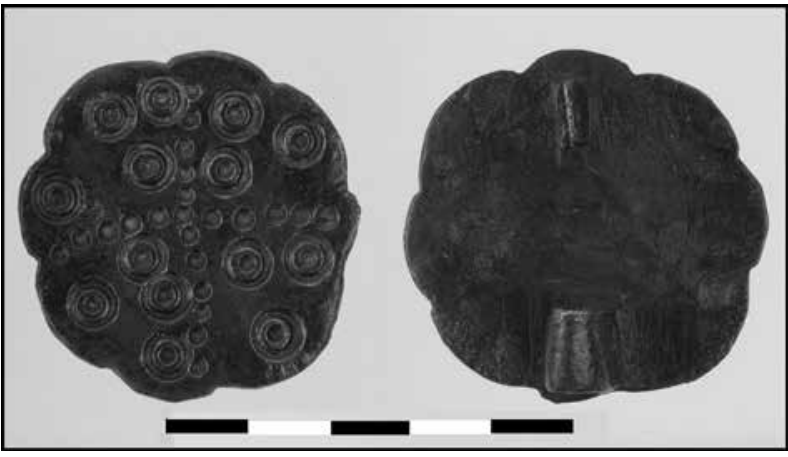

Abb. 4. Scheibenfibel. Komitat Tolna (Foto: Wosinsky Mór Megyei Múzeum)

4. kép. Korongfibula. Tolna megye (fotó: Wosinsky Mór Megyei Múzeum)

(Frankreich, Dép. Aisne) besteht nicht nur aus Punktkreisen, sondern auch aus die Fläche gliedernden gravierten Bogen und Linien. ${ }^{2}$ Bei dem Paar von Amiens (Frankreich, Dép. Somme) war die gesamte Fläche der Fibeln ausschließlich mit Punktkreisen verziert, diese Fibeln unterscheiden sich aber formal in den Einzeldetails des Schwanzes von der Fibel aus Pincehely. ${ }^{3}$ Die Fibel von Montigny en Arrouaise datierte Gertrud Thiry aufgrund des Typs ins 6. Jahrhundert und die von Amiens schon auf etwas später, frühestens in die zweite Hälfte des 6. Jahrhunderts, eher ins 7. Jahrhundert. ${ }^{4}$ Im Gräberfeld TamásiCsikólegelő lag in Grab 29 eine bronzene Vogelfibel (Länge: $3,8 \mathrm{~cm}$ ), die eine dem Exemplar von Pincehely sehr ähnliche stilisierte Form hat: Ebenfalls nur die Schwanzfedern und der Schnabel sind dargestellt. Die Fläche ist mit Ausnahme von einem Punktkreis - der das Auge des Vogels symbolisiert - unverziert (Abb. 5). ${ }^{5}$

Die Form der Vogelfibel von Pincehely liefert wenig Anhaltspunkte für die Herkunft der Fibel. Außer den schon genannten westeuropäischen Parallelen weist auch die für einen Raubvogel typische Gestaltung des Vogelschnabels auf die Beziehung zur westlichen Merowingerwelt hin. Die Punktkreisverzierung ist eine allgemein verbreitete Lösung bei gewissen, mit dem Mediterraneum verbundenen Fibeltypen, ${ }^{6}$ so ist sie eine

2 Die Fibel gehört zur Gruppe der gravierten Vogelfibeln mit ovaler Form. THIRY 1939, Taf. 15.333.

3 Die Fibel gehört zum Typ der gravierten Vogelfibeln mit stark gewölbter Brust. THIRY 1939, Taf. 18.411.

4 THIRY 1939, 45-47 bzw. 50-51.

5 Die Vogelfibel, die in BÓNA-B. HORVÁth 2009 (153-154 und Taf. 67) publiziert wurde, ist eine Fibel unbekannter Herkunft. Ausführlich siehe: RÁcz 2011, 175.

6 Die Punktkreisverzierung war seit römischer Zeit auf Fibeln zu finden und von Westeuropa bis ins Pontusgebiet verbreitet. MÜLLER 2012, 57.

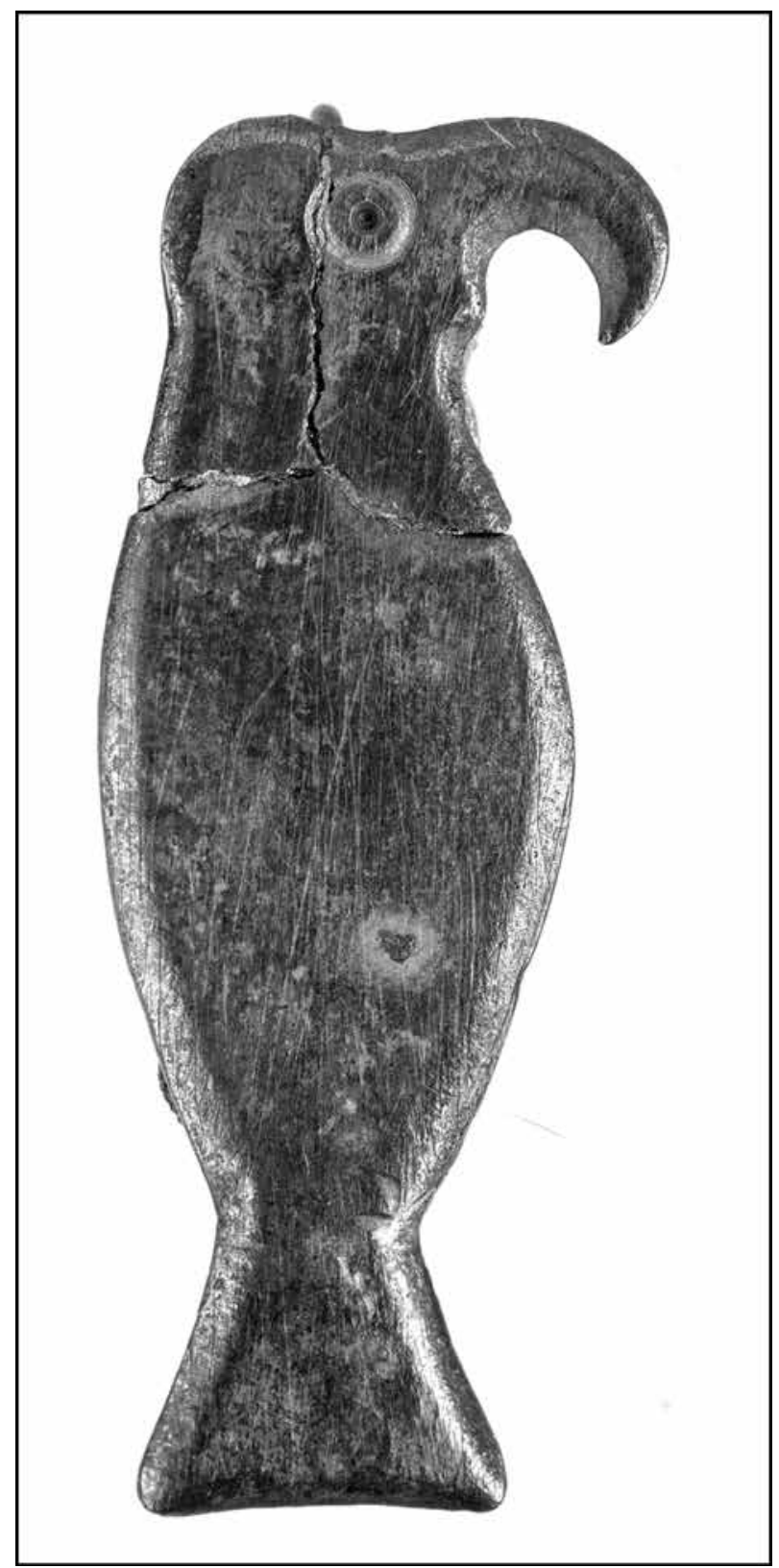

Abb. 5. Vogelfibel. Tamási-Csikólegelő Grab 29 (Foto: Wosinsky Mór Megyei Múzeum)

5. kép. Madárfibula. Tamási-Csikólegelő, 29. sír (fotó: Wosinsky Mór Megyei Múzeum)

der häufigsten Verzierungsarten der Kreuzfibeln des 5.-7. Jahrhunderts ${ }^{7}$ oder der ebenfalls für diese Epoche typischen Tauben-, Pfauen- und Hahnenfibeln. ${ }^{8}$

Bierbrauer 2005, 55-57 und Taf. 1, 3, 4

8 BIERBRAUER 2005, 58-62 und Taf. 5-9. Die Punktkreisverzierung ist auch für das Fundmaterial des Alpengebietes im 5.-7. Jahrhundert typisch. BIERBRAUER 1992, 42. 


\section{Die Pferdefibel}

Mit Punktkreisen verzierte bronzene Pferdefibel, Höhe 2,9 cm, Länge $4 \mathrm{~cm}$, Dicke $0,3 \mathrm{~cm}$. Das nach rechts schauende Pferd ist in Bewegung dargestellt. Alle vier Läufe und auch der Schweif sind schön zu sehen, das Maul ist geöffnet, auch die Ohren sind $\mathrm{zu}$ erkennen. Die Augen sind mit Punktkreisen angegeben und auch die ganze Fibeloberfläche war mit ähnlichen Punktkreisen geschmückt, von denen zwei - oberhalb der Vorder- und Hinterläufe - größer als die übrigen und Doppelkreispunkte sind. Die Hufe waren mit extra Gravierung angegeben und in allen Fällen auch mit Punktkreis hervorgehoben. Die Punktkreise sitzen unregelmäßig auf der Fibel, in einigen Fällen schneiden sie einander. Die Fibel ist abgenutzt, schön patiniert. Auf der Rückseite befinden sich mitgegossene durchgebohrte kleine Ösen in 1,5 cm Abstand voneinander, die die Nadelkonstruktion der Fibel gehalten haben können (Abb. 3).

Die beiden Hauptgruppen der Pferdefibeln bilden die plastischen und die halbplastischen Pferdefibeln. Bei den Ersteren befindet sich die Tierfigur auf der Nadel, allgemein steht sie mit den Läufen auf ihr, wogegen bei den halbplastischen Fibeln die Nadel auf der Fibelrückseite sitzt. ${ }^{9}$ Das Exemplar von Sárszentlőrinc gehört eindeutig zur letzteren Gruppe. Die Grundlage einer weiteren Gruppierung des Typs ist die Darstellungsart des Pferdes - in Bewegung (Schritt, Galopp), im Stand, weidend usw. Am häufigsten sind nur zwei Läufe des Tieres ausgeformt.

Mit dem Erscheinen der Pferdefibeln ist schon im 2. Jahrhundert zu rechnen. ${ }^{10}$ Diese Formtypen speisten sich aus mehreren Quellen: Pferdedarstellungen der Hallstattzeit, aus der griechischen Kunst übernommenes skythisches Pferdebild (Pferd beim Weiden) bzw. völlig vereinfachte Formen, ${ }^{11}$ die nur die zwei Läufe des Pferdes angeben - dieser Typ ist der verbreitetste, von ihm sind Darstellungen im Galopp wie im Stand bekannt. Es handelt sich um einen durch spätantike Wirkung ${ }^{12}$ weit verbreiteten und lange weiterlebenden Gegenstandstyp, der vor allem im

\footnotetext{
9 IBLER 1991, 23; GARAM 2003, 106.

10 PAтEK 1942, 51. Auch Ursula Gertrud Ibler hält es für eindeutig, dass als Formvorläufer der Tierfibeln des 5.-8. Jahrhunderts die römischen emaillierten und Niello-Fibeln des 1.-3. Jahrhunderts betrachtet werden müssen. IBLER 1991 18.

11 PATEK 1942, 51.

12 Werner 1961; RIEMER 2000, 109; IbLeR 1991, 18.
}

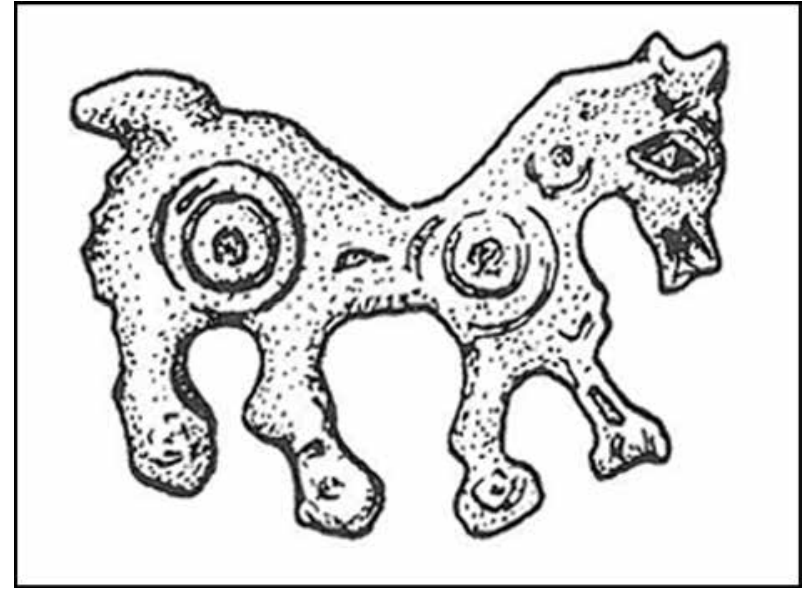

Abb. 6. Pferdefibel. Korinth (nach VINSKI 1967)

6. kép. Lófibula. Korinthosz (VINSKI 1967 nyomán)

Mediterraneum (Italien, ${ }^{13}$ Kroatien ${ }^{14}$ ) selbst noch im 6.-8. Jahrhundert häufig war.

Die nächste Parallele der Pferdefibel von Sárszentlőrinc wurde in Korinth gefunden. Sie wurde zuerst als Kastenbeschlag publiziert, ${ }^{15}$ ist aber vermutlich eher eine Fibel. ${ }^{16}$ Formal stimmt das Exemplar von Korinth mit der Fibel von Sárszentlőrinc überein und ist auch in der Verzierung ähnlich. Es gibt auf ihm die beiden großen Punktkreise oberhalb der Vorder- bzw. Hinterläufe ${ }^{17}$ bzw. den Abdruck kleinerer Punktkreise auf den Hufen und dem Hals des Tieres. Die Augen des Pferdes wurden in rhombischer Form graviert. Die Fibel von Korinth hat Zdenko Vinski ins 6.-7. Jahrhundert datiert $(A b b .6) .{ }^{18}$

Bei den Pferdefibeln sind die Punktkreise die verbreitetste Verzierungsweise. Eine anders geformte, aber so verzierte Pferdefibel ${ }^{19}$ wurde in Delos gefunden, ${ }^{20}$ die ins 6.-7. Jahrhundert datiert werden kann. ${ }^{21}$ Ein weiteres, ähnlich verziertes Exemplar ist aus dem Gebiet Zogeria der

\footnotetext{
13 RIEMER 2000.

14 VINSKI 1967.

15 Davidson 1952, 132, 134 und Taf. 68.935.

16 VINSKI 1967, Taf. X.

17 Selten ist eine Darstellung, wo alle vier Läufe des Pferdes zu sehen sind. In Vinca wurde eine Fibel gefunden, wo alle vier Läufe des Pferdes - bzw. in diesem Fall der Pferde - gezeigt waren, hier handelt es sich aber um einen völlig anderen Typ: Die Fibel von Vinca stellt zwei einander gegenüberstehende Pferde dar. In der Verzierung ähnelt sie jedoch der von Sárszentlőrinc, auch auf ihr finden sich Punktkreise. VINSKI 1967, Taf. X.

18 VINSKI 1967, 18

19 Die Form ist nicht nur als Pferd zu interpretieren; vorstellbar ist, dass irgendeine Großkatzenart dargestellt ist.

20 Davidson 1952, 270 und Taf. 113.2173.

21 VINSKI 1967, 18.
} 


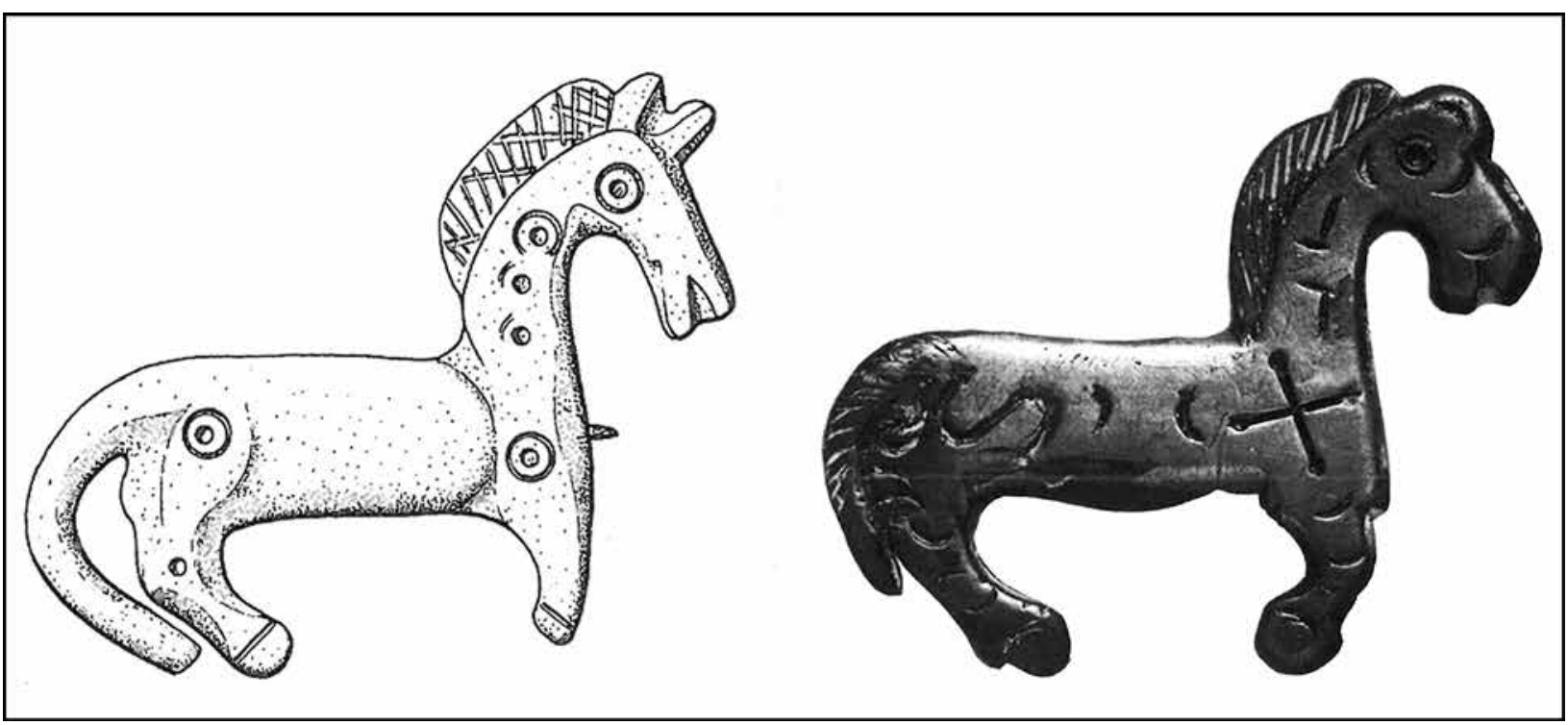

Abb. 7. Pferdefibeln. Castel Trosino (nach PArOLI-Ricci 2007)

7. kép. Lófibulák. Castel Trosino (PAROLI-Ricci 2007 nyomán)

Spetses-Insel bekannt, das Anna Avraméa ins 7. Jahrhundert datiert hat. ${ }^{22}$ Mehrere Stücke sind aus dem langobardenzeitlichen Italien bekannt, ${ }^{23}$ die in Form und Bearbeitung ein vielfarbiges Bild zeigen. Die Pferdefibel aus Castel Trosino Grab $171^{24}$ unterscheidet sich der Form nach von der aus Sárszentlórinc - sie ist nur mit zwei Läufen, anderer Mähne und Schweif, dagegen gleichfalls mit geöffnetem Maul dargestellt und sogar die beiden Ohren sind zu sehen -, aber ihre Verzierung ist ähnlich. Sie ist die einzige Pferdefibel aus dem Gräberfeld von Castel Trosino, 25 die mit Punktkreisen verziert und auch ihr Auge so bezeichnet war. Eine in der Form einfache, aber eindeutig ein Pferd darstellende Fibel mit zwei Punktkreisen befand sich in Bisaccia Grab 17 (Abb. 7). ${ }^{26}$

Ellen Riemer rechnet mit dem frühesten Erscheinen der von ihr untersuchten Pferdefibeln bereits ab dem 5 . Jahrhundert, ${ }^{27}$ die genaue Datierung stößt jedoch auf Schwierigkeiten wegen der allgemeinen Verbreitung der beigabenlosen Bestattungen. ${ }^{28}$ Unter den norditalischen

22 AVRAMÉA 1997, 88.IVe2 und 91.

23 Atella, Bisaccia Grab 17, Castrovillari Grab 2, Castel Trosino Grab 171. RIEMER 2000, 109.

24 PAROLI-RicCI 2007, 99-100 und 128, Taf. 211.

25 Insgesamt wurden dort sechs Pferdefibeln gefunden: Grab 11, 45, 121, 124, 136 und 171. PAROLI-Ricci 2007, Taf. 211.

26 RIEMER 2000, Taf. 79.

27 Die Existenz im 5. Jahrhundert der Formen in Fundkomplexen des 6. Jahrhunderts setzt auch Ursula Gertrud Ibler voraus. IBLER 1991, 19.

28 Zur Untermauerung ihrer Behauptung erwähnt sie einen pannonischen Fund des 5. Jahrhunderts, eine Pferdefibel von
Funden bezeichnet sie den von Venusio als frühesten und datiert ihn aufgrund der Begleitfunde auf das Ende des 5., den Anfang des 6. Jahrhunderts. Die Stücke von Castel Trosino legt sie nach Volker Bierbrauer ${ }^{29}$ auf um 600, in die erste Hälfte des 7. Jahrhunderts. ${ }^{30}$ Auch Ursula Gertrud Ibler datiert die Zweitblüte der Pferdefibeln aufgrund der zahlreichen italischen Stücke bzw. der Fibeln von Bled und Keszthely-Fenékpuszta ${ }^{31}$ ähnlich, auf das Ende des 6., in die erste Hälfte des 7. Jahrhunderts.

Im Karpatenbecken kennen wir aus dieser Periode nur einige weitere Pferdefibeln, die László Barkóczi veröffentlichte, gleichfalls aus Keszthely-Fenékpuszta, aber aus dem HorreumGräberfeld, ${ }^{32}$ und eine aus dem Gräberfeld von Ödenkirche-Flur ${ }^{33}$ bzw. noch ein Stück, ebenfalls aus der Umgebung von Keszthely, aber ohne archäologischen Kontext. ${ }^{34}$ In Form und Verzierung unterscheidet sie sich vom Exemplar aus Sárszentlőrinc, denn sie gehört zum mit zwei Läufen im Galopp dargestellten Typ und ist mit einfachen gravierten Linien verziert (gezähnte Ver-

Keszthely-Fenékpuszta. RIEMER 2000, 110. Das Exemplar von Keszthely-Fenékpuszta wurde 1973 gefunden, in einer Zerstörungsschicht bei der Freilegung von Gebäude II, das auf 455 datiert wird. GÁSPÁr 1979, 313 und Abb. 1.

29 BiERBRAUER 1980, 98.

30 RIEMER 2000, 110.

31 IBLER 1991, 24-25.

32 BARKÓCZI 1968

33 Grab 2000/126: MÜLLER 2014, 66-67 und Taf. 22.

34 FETTICH 1951, Taf. 21.4. Es gibt auch eine weitere, aus zwei gegenüberstehenden Tierköpfen zusammengesetzte Tierfibel in der Sammlung, die auch als Pferd bestimmt wird. Feтtich 1951, Taf. 21.1. 
zierung, die eine Beziehung der Fibel mit den südtransdanubischen gezähnten Flechtbandbeschlägen bedeutet ${ }^{35}$ ). Im Gegensatz $\mathrm{zu}$ dem von Sárszentlőrinc steht dieses Exemplar in näherer Beziehung zu den Stücken von Castel Trosino. ${ }^{36}$ Es ist als Datierungsanhaltspunkt gut brauchbar, weil es mit einer S-Fibel Typ Keszthely ${ }^{37}$ zusammen gefunden wurde, welchen Typ die Forschung ins letzte Drittel des 6. Jahrhunderts datiert. ${ }^{38}$ Den Typ hat Tivadar Vida - mit mehreren anderen Tierfibeln (Pfau, Taube, Hahn) - als Trachtelement romanisierter Frauen bestimmt, das auch christliche Symbolik an sich trägt ${ }^{39}$ und von den Beziehungen der Region zum Balkan und Alpengebiet zeugt. ${ }^{40}$

Die Fibel von Sárszentlórinc passt demnach in den Kreis der auch bisher aus dem Mediterraneum bekannten Pferdefibeln. Ihre Verzierungsweise war weit verbreitet, bei ihrer Form handelt es sich jedoch um einen seltenen Typ. Man kann sie aufgrund der angeführten Parallelen wahrscheinlich ans Ende des 6. oder in die erste Hälfte des 7. Jahrhunderts datieren, Genaueres lässt sich aber ohne Kenntnis der Fundumstände nicht sagen. Die bisher in Pannonien gefundenen Stücke kamen in Umgebungen mit starker Bindung an spätrömische Traditionen und mit mediterranen Beziehungen im Fundmaterial vor, und das trifft allgemein auch auf die ausländischen Exemplare zu.

\section{Die Scheibenfibel}

UnregelmäßigebronzeneAchtpass-Scheibenfibel, Größe 2,2 × 2,1 cm. Oberfläche gerade und durch Kreispunzen etwa in Kreuzform in vier Felder geteilt. In diesen saßen ungleichmäßig verteilt je drei bzw. je vier Punktkreise, von denen zwei die Kreispunzen teils verdecken, also hatte man im zweiten Gang die Fibel mit der Kreispunze verziert. In der Achse der Rückseite befinden sich die mitgegossene Federhalteöse und das Nadelhalterblech mit umgebogenem Ende. Die Nadel fehlt (Abb. 4).

Es sind mehrere Scheibenfibeln in ähnlicher Ausführung wie die aus Kom. Tolna bekannt. In Gyirmót-Homokdomb kam im Grab 31 des

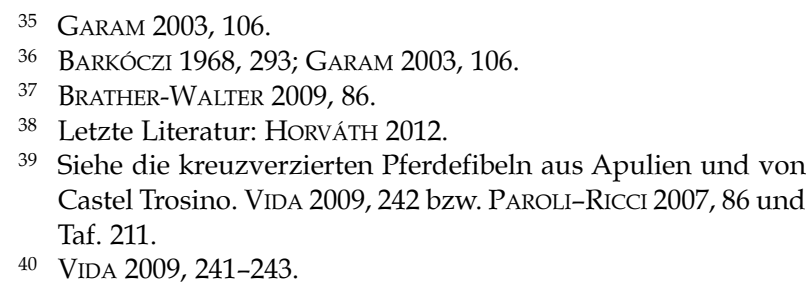

Gräberfeldes aus dem 6. Jahrhundert eine gleichfalls mit Punktkreisen verzierte 14-PassScheibenfibel zum Vorschein, allerdings ohne die viergeteilte Verzierung des Exemplars aus Kom. Tolna. Die andere Scheibenfibel ${ }^{41}$ aus Grab 31 von Gyirmót-Homokdomb war mit gravierten geometrischen Motiven verziert, bei denen wiederum die Vierteilung der Oberfläche zu erkennen war. Das Grab hat Péter Tomka zusammen mit dem ganzen Gräberfeld in die erste Hälfte/ Mitte des 6. Jahrhunderts datiert. ${ }^{42}$ Im Kranjer Gräberfeld Grab 297 lag eine ebenfalls auf der ganzen Oberfläche mit Punktkreisen verzierte, unregelmäßig kreisförmige (eventuell abgenutzt passförmige) Fibel, ${ }^{43}$ die Zdenko Vinski für ein typisches Trachtelement der lokalen romanisierten Frauen der Mitte/zweiten Hälfte des 6. Jahrhunderts hält $(A b b .8) .{ }^{44}$ Weitere Fibeln sind aus dem Ostalpenraum bekannt, aus Teurnia Grab 23/73 ${ }^{45}$ und Invillino. ${ }^{46}$ Erstere ist ein einfaches kreisförmiges Stück mit einer Zelle in der Mitte, umgeben von Punktkreisen, das auf das Ende des 6. Jahrhunderts datiert werden kann. ${ }^{47}$ Das Exemplar von Invillino ist ebenfalls einfach kreisförmig, mit einem Doppelkreis im Mittelpunkt und Punktkreisen im regulären Kreis. ${ }^{48}$ Volker Bierbrauer verbindet es eindeutig mit der romanisierten Bevölkerung und datiert es mangels genauer Datierungsanhaltspunkte ins 6.-7. Jahrhundert. ${ }^{49}$ Wegen der einfacheren Aus-

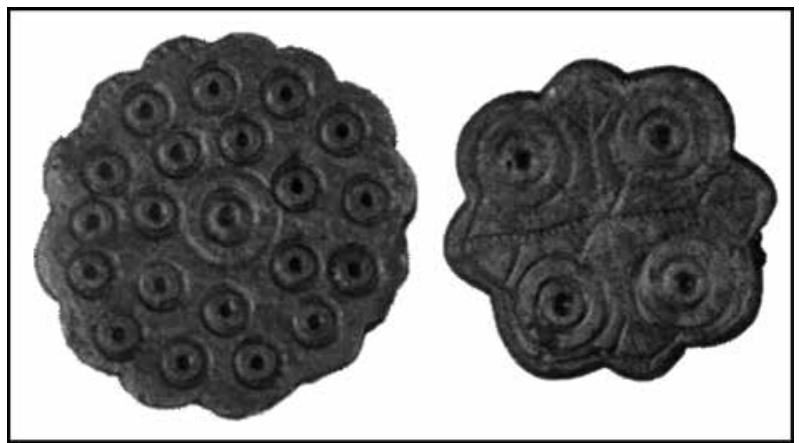

Abb. 8. Fibeln. Gyirmót-Homokdomb Grab 31 (nach ToMKA 2008)

8. kép. Fibulák. Gyirmót-Homokdomb, 31. sír (TOMKA 2008 nyomán)

41 Sog. Vierpassfibel, die Péter Tomka nach István Bóna und der Parallele vom Fundort Mannheim-Strassenheim den fränkisch-alemannischen Gebieten zuordnete. TOMKA 2005, 252.

42 TOMKA 2005, 252-253, 262.

43 StARe 1980, 72 und Taf. 89.

44 VINSKI 1980, 94-95.

45 Piccottini 1976, 29-30 und Taf. 15.5.

46 Bierbrauer 1987, 146 und Taf. 47.

47 Piccottini 1976, 95; Ibler 1991, 35.

48 Bierbrauer 1987, 146 und Taf. 47.

49 Bierbrauer 1987, 146. 


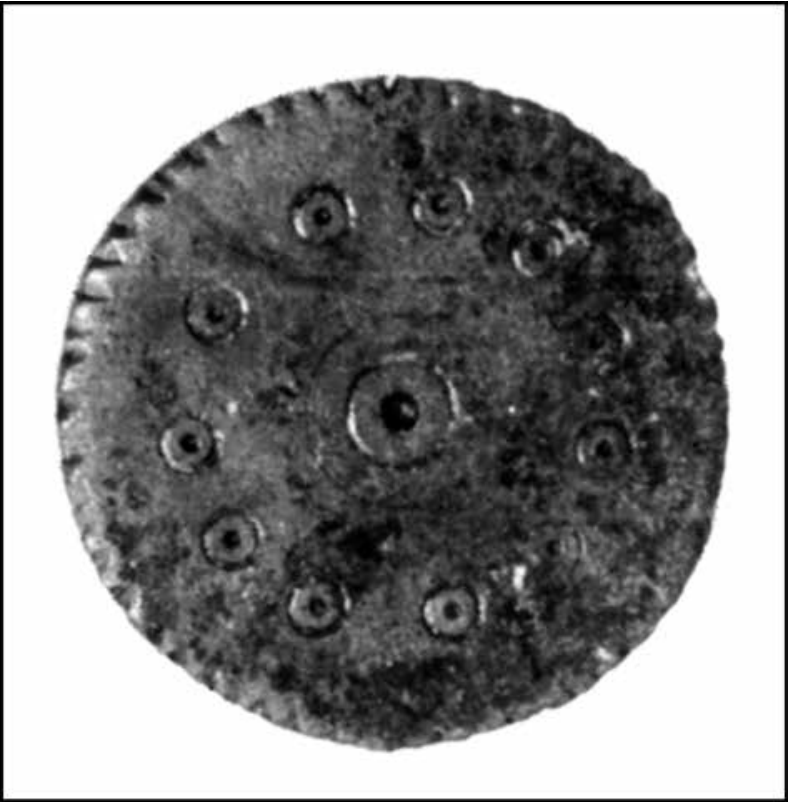

Abb. 9. Scheibenfibel. Invillino (nach BIERBRAUER 1987)

9. kép. Korongfibula. Invillino (BIERBRAUER 1987 nyomán)

führung wurde erwogen, dass dieser Fibeltyp als Imitation der goldenen Einlagenscheibenfibeln erschienen ist (Abb. 9). ${ }^{50}$

Aufgrund der genannten Parallelen kann auch die Scheibenfibel - wie die Vogel- und Pferdefibel - am wahrscheinlichsten in die zweite Hälfte des 6. Jahrhunderts datiert werden.

\section{Zusammenfassung}

Die drei Fibeln können wegen des völligen Fehlens des archäologischen Kontextes nur aufgrund ihrer Parallelen datiert werden: So werden die Vogel-, Pferde- und Scheibenfibel in der zweiten Hälfte des 6. oder am Anfang des 7. Jahrhunderts geschaffen worden sein.

Sowohl aufgrund der Datierung als auch der Verzierung sind die drei Fibeln stark mit der sog. Gruppe mit Punktkreisverzierung verbunden, die vor allem von den Gräberfeldern der Umgebung von Keszthely bekannt ist. Auf die Konzentration der punktkreisverzierten Gegenstände in der Umgebung von Keszthely wurde schon Nándor Fettich aufmerksam, der vor allem wegen gewisser typologischer Parallelen die Herkunft der Gruppe aus dem Pontusgebiet

50 BIERBRAUER 1987, 146. Der Scheibenfibel von Teurnia ähnliche - teils einlagenverzierte - Stücke können den ersten Schritt der vereinfachenden, umgestaltenden Verzierung bedeuten. PiccotTini 1976, 95. annahm. ${ }^{51}$ Zwischen den Gegenständen vermutete er aufgrund von technologischen Details (Gestaltung der Punktkreise, Verzierungsdichte) eindeutige Werkstattbeziehungen. ${ }^{52}$ Joachim Werner nahm demgegenüber für die byzantinische Herkunft der Gegenstände Stellung und datierte sie ins 6.-7. Jahrhundert. ${ }^{53}$ Manfred Menke erwog wegen der Verzierung - und des völligen Fehlens des für die Gegenstände der Epoche typischen Tierstils -, dass sie in den Werkstätten der weiterlebenden antiken Bevölkerung entstanden sein könnten, schloss aber auch die Möglichkeit solcher germanischen Gemeinschaften nicht aus, die den Tierstil einfach nicht verwendeten $(A b b .10){ }^{54}$

Róbert Müller beschäftigt sich bei seinem Überblick der Ausgrabungen der Gräberfelder von Fenékpuszta durch Vilmos Lipp und Árpád Csák auch ausführlich mit der Problematik der Gegenstände mit Punktkreisverzierung. Er hält es nicht für eindeutig bewiesen, dass die Gruppe der Gegenstände mit Punktkreisverzierung als Fundmaterial der am Ort weiterlebenden spätantiken Bevölkerung zu betrachten ist. Er sieht in ihnen eher Erzeugnisse von Werkstätten in der zweiten Hälfte bis zum Ende des 6. Jahrhunderts, die die spätrömischen Traditionen fortsetzten, aber sowohl die weiterlebenden als auch die germanischen Gemeinschaften bedienten. ${ }^{55}$ Die Größe der Kreispunzen der drei Fibeln ist verschieden, wenn auch nicht erheblich. Unterschiedlich ist auch die Tiefe, in welche sie eingeschlagen wurden.

Die Punktkreisverzierung kann nicht ausschließlich mit den spätrömischen Traditionen oder spätantiken Werkstätten verbunden werden. Ausgehend von ihrer Einfachheit konnte sie in geographisch verschiedenen, mit den Romanisierten nicht in Verbindung zu bringenden Gebieten ${ }^{56}$ vorkommen, in Gegenstands-

51 FETTICH 1951, 161.

52 Ein großer Teil der Gegenstände entstand mit identischem Punzierungswerkzeug. FetTich 1951, 161. Dies bezweifelte aufgrund seiner Beobachtungen: MÜLLER 2012, 56.

53 FUCHS-WERNER 1950, 63; später WERNER 1961, 53.

54 MENKE 1990, 193.

55 MÜLlER 2012, 57-58.

56 Verbreitung der Fibeln mit Punktkreisverzierung in der Großen Ungarischen Tiefebene und in Siebenbürgen im 5.-7. Jahrhundert, auch wenn in diesem Fall der spätantik/byzantinische Einfluss natürlich nicht völlig auszuschließen ist. CSEH 1990, Karte XIII und Liste 13. Vielleicht ein extremes Beispiel, aber den allgemein verbreiteten Charakter der Verzierung zeigt eine in Alaska gesammelte Schnitzerei aus dem 19. Jahrhundert. HiLl 2011, 415. 


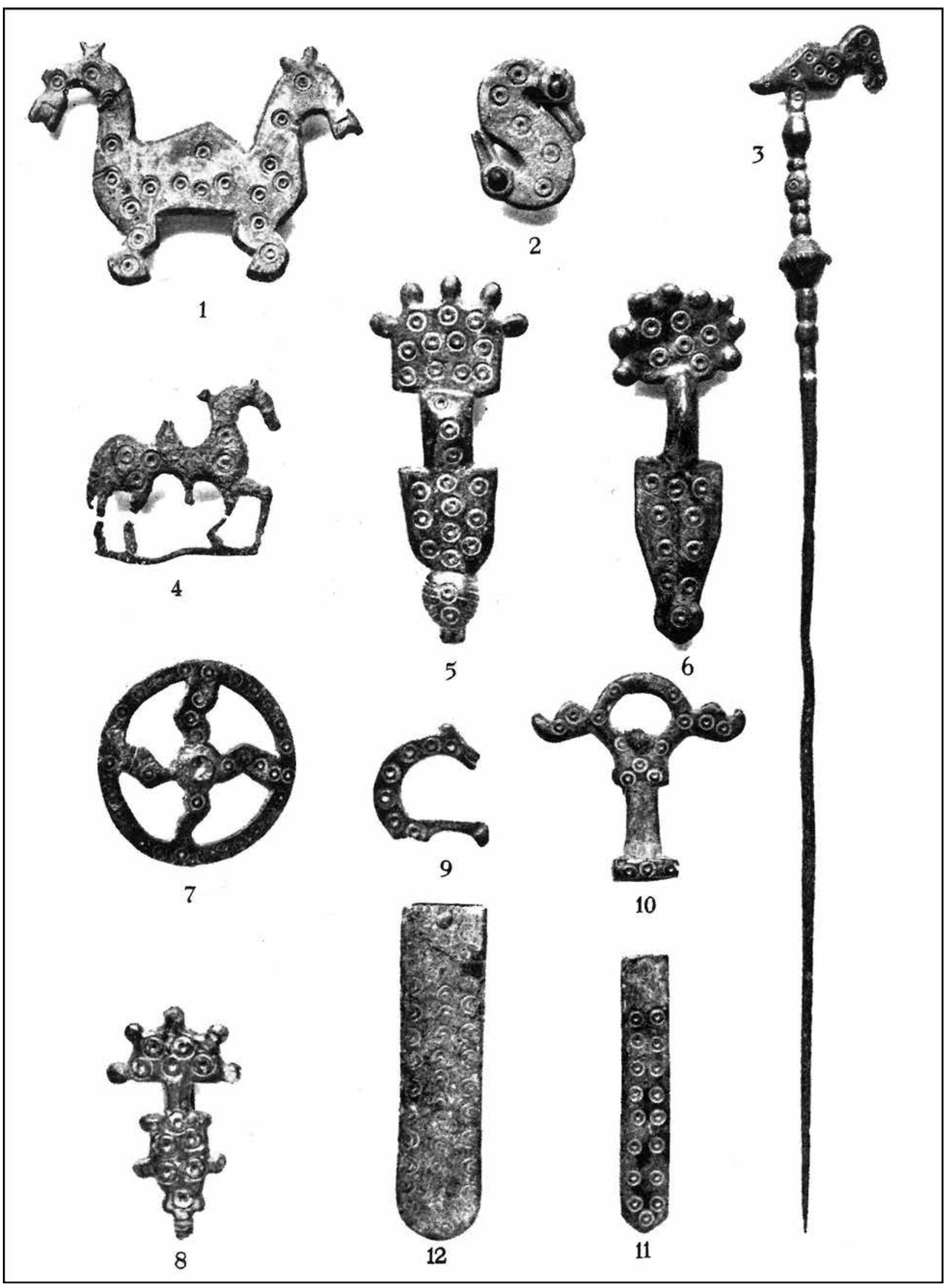

Abb. 10. Funde mit Punktkreisverzierung aus Keszthely und Umgebung (nach FetTich 1951) 10. kép. Pontkördíszes leletek Keszthelyről és környékéről (FETTICH 1951 nyomán) 


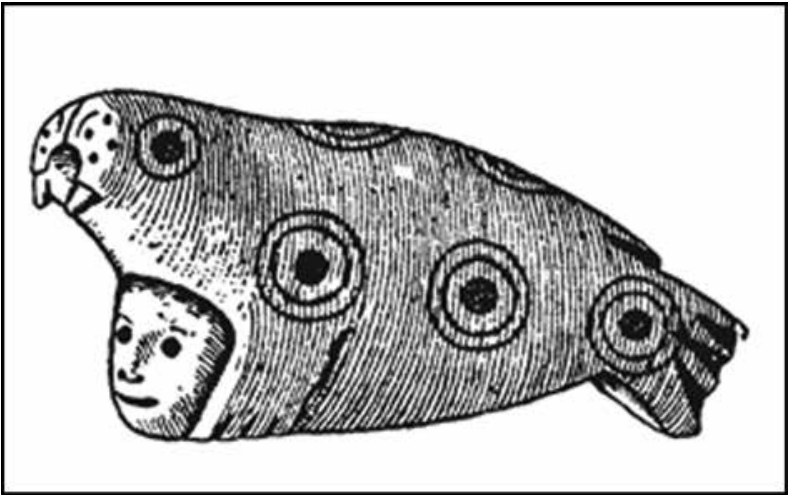

Abb. 11. Elfenbeinschnitzerei von Walross Inua (Geist oder Seele). Walross Inua, Alaska (nach HiLl 2011)

11. kép. Szellemet vagy lelket ábrázoló elefántcsont faragvány. Walross Inua, Alaszka (Hill 2011 nyomán)

gruppen unterschiedlichen ${ }^{57}$ Typs und Grundmaterials $(A b b .11)$. Gerade wegen ihrer Einfachheit war sie die entsprechende Lösung zur Verzierung unterschiedlicher Oberflächen, wo entweder der Sachverstand für die oder das Bedürfnis nach der Anwendung der periodentypischen komplizierten Zierstile (Flechtornamentik, Tierstile usw.) fehlte. Die Anwendung der Punktkreisverzierung kann jedoch nicht nur mit der horizontalen (kulturelle oder ethnische Gruppen, Traditionen), sondern auch der vertikalen (Vermögen und Rang) ${ }^{58}$ Gliederung der Gesellschaft zusammengehangen haben. Das
Material, die Ausführung, die die Verzierung betreffenden (einander deckende Punzen, schräge Linien, unterschiedliche Einschläge usw.) und besonders bei der Scheibenfibel zu beobachtenden Ungenauigkeiten der Form weisen auf einfache und billige Ausführung der Gegenstände hin. Die Punktkreise kommen allgemein auf einfach herzustellenden bronzenen Gegenständen vor, deren meist einzige Verzierung sie sind - wie eben auch bei den in diesem Artikel untersuchten Fibeln. ${ }^{59}$ Auf in der Qualität und im Material (Gold, Silber) wirklich wertvollen Gegenständen kommen sie als Hauptzierelement nicht vor. Die sehr unterschiedlichen Objekttypen und Materialgruppen mit Punktkreisornament in abgelegenen Gebieten können nachweisen, dass die gleiche Dekoration in verschiedenen Milieus verschiedene Bedeutung haben könnte.

Die drei Fibeln können in einem Medium entstanden sein, das gleichzeitig aus den lokalen und den mediterranen, spätantiken und barbarischen Traditionen schöpfte, ${ }^{60}$ wo die beiden Geschmackswelten - wenn von so etwas überhaupt die Rede sein kann - gar nicht mehr getrennt werden mussten und/oder konnten. Die Punktkreisverzierung mochte als eine Art „Mangelkunst" eine akzeptable Lösung für zusammengesetzte Gemeinschaften gewesen sein, die sich aus Gruppen unterschiedlichen Hintergrundes gebildet hatten.

\section{LITERATUR}

AvramÉA, ANNA

1997 Peloponnèse du IVe au VIII siècle. Changements et persistences. Byzantina Sorbonensia 15. Paris. BARKÓCZI, LÁSZLÓ

1968 A $6^{\text {th }}$ Century Cemetery from Keszthely-Fenékpuszta. Acta Archaeologica Academiae Scientiarum Hungaricae (Budapest) 20, 275-311.

BIERBRAUER, VOLKER

1980 Frühgeschichtliche Akkulturationsprozesse in den germanischen Staaten am Mittelmeer (Westgoten, Ostgoten, Langobarden) aus der Sicht des Archäologen. In: Atti del $6^{\circ}$ congresso internazionale di studi sull'alto medioevo, Mailand 1978. Spoleto, 89-105.

1987 Invillino-Ibligo in Friaul I. Die römische Siedlung und das frühmittelalterliche Castrum. Münchener Beiträge zur Vor- und Frühgeschichte 38. München.

1992 Zwei romanische Bügelfibeltypen des 6. und 7. Jahrhunderts im mittleren Alpenraum. Ein Beitrag zur Kontinuitäts- und Siedlungsgeschichte. In: Lippert, A.-Spindler, K. (Hrsg.): Festschrift zum 50-jährigen Bestehen des Institutes für Ur- und Frühgeschichte Innsbruck der Leopold-Franzens-Universität Innsbruck. UPA 8. Innsbruck, 37-74.

57 Der Punktkreis ist eines der verbreitetsten Zierelemente der Geweihkämme des 6.-7. Jahrhunderts, er ist aber auch für die frühawarenzeitlichen Gürtelbeschläge typisch. GARAM 2001, 119-124.

58 Das Problem hat schon gezeigt: VIDA 2009, 243.
59 Im Gegensatz zu den Fibeln finden sich die Punktkreise auch auf Gürtelzierden von hervorragender Qualität, allerdings im seltensten Fall als Hauptzierelement. GARAM 2001, 122123.

60 VIDA 2011, 643 
2005 Kreuzfibeln und Tierfibeln als Zeugnisse persönlichen Christentums in der Romania Oberitaliens (5.-7. Jahrhundert). In: Gelichi, S. (Hrsg.): L'Italia altomedievale tra archeologia e storia. Studi in ricordo di Ottone D'Assia, 55-77.

BÓNA, IsTVÁN-B. HORVÁTH, JOLÁN

2009 Langobardische Gräberfelder in West-Ungarn. Monumenta Germanorum Archaeologica Hungariae 6. Budapest.

BRATHER-WALTER, SUSANNE

2009 Schlange - Seewesen - Raubvogel? Die S-förmigen Kleinfibeln der älteren Merowingerzeit. Zeitschrift für Archäologie des Mittelalters (Köln) 37, 47-110.

CSEH JÁNOS

1990 Adatok az V-VII. századi gepida emlékanyag egységéhez. Szolnok Megyei Múzeumi Évkönyv (Szolnok), 29-77.

DAVIDSON, GLADYS R.

1952 Corinth. Results of Excavations Conducted by the American School of Classical Studies at Athens. Volume 12: The Minor Objects 12. Princeton, New Jersey.

FETTICH NÁNDOR

1951 Régészeti tanulmányok a késői hun fémmúvesség történetéhez. Archaeologia Hungarica 31. Budapest.

FUCHS, SIEGFRIED-WERNER, JOACHIM

1950 Die langobardischen Fibeln aus Italien. Berlin.

GARAM, ÉVA

2001 Funde byzantinischer Herkunft in der Awarenzeit vom Ende des 6. bis zum Ende des 7. Jahrhunderts. Monumenta Avarorum Archaeologica 5. Budapest.

2003 Avar kori fibulák (Awarenzeitliche Fibeln). Archaeologiai Értesítő (Budapest) 128, 95-123.

GÁSPÁR, DOROTTYA

1979 Ein spätrömischer Kästchenbeschlag-Fund von Fenékpuszta. Acta Archaeologica AcademiaeScientiarum Hungaricae (Budapest) 31, 313-327.

HILL, ERICA

2011 Animals as Agents: Hunting Ritual and Relational Ontologies in Prehistoric Alaska and Chukotka. Cambridge Archaeological Journal (Cambridge) 21/3, 407-426.

HORVÁTH ESZTER

2012 Ékkő- és üvegberakásos ötvösmunkák a Kárpát-medence hun kori és kora Meroving-kori leletanyagában. Doktori disszertáció, ELTE Budapest. Kézirat.

IBLER, URSULA GERTRUD

1991 Studien zum Kontinuitätsproblem am Übergang von der Antike zum Mittelalter im Nord- und WestJugoslawien. Inauguraldissertation zur Erlangung der Doktorwürde. Bonn.

MENKE, MANFRED

1990 Zu den Fibeln der Awarenzeit aus Keszthely. Wosinsky Mór Múzeum Évkönyve (Szekszárd) 15, 187214.

MÜLLER, RÓBERT

2012 Die Gräberfelder vor der Südmauer der Befestigung von Keszthely-Fenékpuszta. Castellum Pannonicum Pelsonense 1. Budapest-Keszthely-Leipzig-Rahden.

2014 Das Gräberfeld von Keszthely-Fenékpuszta, Ödenkirche-Flur. Castellum Pannonicum Pelsonense 5. Budapest-Keszthely-Leipzig-Rahden.

PAROLI, Lidia-Ricci, MARCO

2007 La necropoli altomedievale di Castel Trosino (Vol. 1-2). Ricerche di Archeologia Altomedievale e Medievale 32-33. Firenze, All'Insegna del Giglio.

PATEK ERZSÉBET

1942 A pannoniai fibulatípusok elterjedése és eredete. Dissertationes Pannonicae 2/19. Budapest.

PICCOTTINI, GERNOT

1976 Das spätantike Gräberfeld von Teurnia St. Peter in Holz. Archiv für Vaterländische Geschichte und Topographie 66. Klagenfurt.

Pohl, WALter-ERhart, Peter

2005 Die Langobarden - Herrschaft und Identität. Forschungen zur Geschichte des Mittelalters 9. Wien.

RÁCZ ZsÓFIA

2011 Madárfibulák a gepida korból (Vogelfibeln aus gepidischer Zeit). Archaeologiai Értesítő (Budapest) 136, 165-179.

RIEMER, ELLEN

2000 Romanische Grabfunde des 5.-8. Jahrhunderts in Italien. Internationale Archäologie 57. Rahden/Westf.

StARE, VIDA

1980 Kranj: nekropola iz časa preseljevanja ljudstev. Katalogi in monografije. Narodni Muzej 24. Ljubljana. 
THIRY, GERTRUD

1939 Die Vogelfibeln der germanischen Völkerwanderungszeit. Rheinische Forschungen zur Vorgeschichte. Bonn.

TOMKA, PÉTER

2005 Langobardenforschung in Nordwestungarn. In: POHL-ERHART 2005, 247-264.

VIDA, TIVADAR

2009 Local or Foreign Romans? The Problem of the Late Antique Population of the $6^{\text {th }}-7^{\text {th }}$ Centuries AD in Pannonia. In: Quast, D. (Hrsg.): Foreigners in Early Medieval Europe: Thirteen International Studies on Early Medieval Mobility. Monographien des Römisch-Germanischen Zentralmuseums 78. Mainz, 233259.

2011 Das Mitteldonaubecken im Wandel zwischen dem 4. und 6. Jahrhundert n. Chr. In: Konrad, M.-Witschel, Chr. (Hrsg.): Römische Legionslager in den Rhein- und Donauprovinzen - Nuclei spätantikfrühmittelalterlichen Lebens? München, 615-648.

VINSKI, ZDENKO

1967 Kasnoanticki starosjedioci u salonitanskoj regiji prema arheoloskoj ostavistini predslavenskog supstrata. Vjesnik Za Arheologiju I Historiju Dalmatinsku (Split) 69, 5-86.

1980 Betrachtungen zur Auswertung des Grabbeigabenfundstoffes der völkerwanderungszeitlichen Nekropole in Kranj. In: STARE 1980, 91-105.

WERNER, JOACHIM

1961 Katalog der Sammlung Diergardt: Völkerwanderungszeitlicher Schmuck. Bd. 1: Die Fibeln. Berlin.

\title{
EGYSZERÛ́ VAGY IGÉNYTELEN? \\ A 6. SZÁZADI „PONTKÖRDÍSZÍTÉSRŐL“ HÁROM TOLNA MEGYEI FIBULA KAPCSÁN
}

\author{
KONCZ ISTVÁN - ÓdOR JÁNOS GÁBOR
}

A közelmúltban Tolna megyében szórványként került a felszínre három, díszítése és kora alapján összekapcsolható fibula. A fibulák a régészeti kontextus teljes hiányában csupán párhuzamaik alapján keltezhetők, így a madár-, a ló-, illetve a korongfibula egyaránt a 6. század második felében, a 7. század elején készülhetett.

A három fibula keltezése és díszítése alapján is erősen kötődik az elsősorban a Keszthely környéki temetőkből ismert, ún. pontkördíszes csoporthoz. A pontkördíszes tárgyak Keszthely környéki csoportosulására már Fettich Nándor felfigyelt, aki elsősorban bizonyos tipológiai párhuzamok alapján a csoport Pontus-vidéki eredetét feltételezte (FeTTich 1951, 161.). Technológiai részletek figyelembevételével (a pontkörök kialakítása, a díszítés súrúsége) egyértelmú múhelykapcsolatot feltételezett a tárgyak között. Joachim Werner ezzel ellentétben a tárgyak bizánci eredete mellett foglalt állást, és a 6-7. századra keltezte azokat. Manfred Menke a díszítés alapján - valamint a korszak tárgyaira jellemző állatstílus hiányában felvetette, hogy tovább élő antik népesség múhelyeiben készülhettek, ugyanakkor nem zárta ki olyan germán közösségek létezésének lehetőségét sem, amelyek egyszerúen nem alkalmazták az állatstílust.

Müller Róbert a Lipp Vilmos- és Csák Ádám-féle fenékpusztai temetők áttekintésekor részletesen foglalkozott a pontkördíszes tárgyak problematikájával. Nem látja egyértelmúen bizonyítottnak, hogy a pontkördíszes tárgyak csoportja a helyben tovább élő, késő antik népesség leletanyagának tekinthető, inkább olyan, a 6. század második felében-végén létező múhelyek termékeiként tekint rájuk, amelyek a késő római hagyományokat folytatták, de egyaránt kiszolgálták a tovább élő és a germán közösségeket is. A három fibula körponcolóinak mérete eltér egymástól - ha nem is nagymértékben. Szintén mu- tatkozik különbség abban, milyen mélységben ütötték be őket.

A pontkörös díszítés nem köthető kizárólagosan a késő római hagyományokhoz vagy késő antik múhelyekhez. Egyszerúségéból adódóan egymástól függetlenül jelen lehetett földrajzilag elkülönülő, a romanizáltakkal kapcsolatba nem hozható területeken, típusukban és alapanyagukban eltérő tárgycsoportokon. Éppen egyszerúsége miatt megfelelő megoldást jelentett különböző felületek díszítésére ott, ahol hiányzott akár a szakértelem, akár az igény a korszakra jellemző, összetett díszítőstílusok (fonatornamentika, állatstílusok) alkalmazásához. A pontkörös díszítés alkalmazása ugyanakkor nem csak a társadalom horizontális (kulturális csoportok, etnikumok, hagyományok), hanem vertikális (vagyon és rang) tagozódásával is összefüggésben állhatott. A vizsgált fibulák anyaga, kivitele, a díszítésbeli (egymást fedő poncok, ferde vonalak, eltérő beütések stb.) és különösen a korongfibula esetében megfigyelhető formai pontatlanságok a tárgyak egyszerú és olcsó kivitelére utalnak. A pontkörök általában fő díszítő motívumként egyszerúen kivitelezhető, bronzból készült tárgyakon jelennek meg, amelyeknek rendszerint egyedüli díszítését jelentik - mint a vizsgált fibulák esetében is. Igazán jó minőségú, értékes anyagból készült tárgyak esetében inkább csak kiegészítő díszítésként jelennek meg.

A három fibula olyan közegben készülhetett, amely egyaránt merített a lokális és mediterráneumi, késő antik és barbár hagyományokból, ahol a két ízlésvilág - ha egyáltalán beszélhetünk ilyenről - elkülönítésére már nem volt szükség és/vagy lehetőség. A pontkörös díszítés mint egyfajta "hiánymúvészet" elfogadható megoldást jelenthetett az összetett, különböző hátterú csoportokból felépülő közösségek számára. 